\title{
Analisa Karakteristik Getaran Pada Mesin Asphalt Mixing Plant Tipe Apollo ANP- 1500 Berdasarkan Kapasitas Pembuatan Aspal Jalan Pada Daerah Horizontal, Vertikal dan Longitudinal Berdasarkan Time Domain
}

\author{
Suriady Sihombing ${ }^{1, *}$, Wilson Nababan ${ }^{1}$, Ros Anita Sidabutar ${ }^{2}$, Partahi \\ Lumbangaol $^{2}$, Yetti R. Saragih ${ }^{2}$, Salomo Simanjuntak ${ }^{2}$ \\ Prodi Teknik Mesin Universitas HKBP Nommensen, Medan 20234 \\ Prodi Teknik Sipil Universitas HKBP Nommensen, Medan 20234 \\ *surihombing@gmail.com
}

\begin{abstract}
Asphalt mixing plant machine is a tool used to process several materials into road asphalt, where it is necessary to know how to analyze the vibration characteristics of the asphalt mixing plant machine based on the capacity of making asphalt road in horizontal, vertical and longitudinal areas based on the time domain. The research method is carried out by collecting data on the amount of deviation, speed and acceleration that arise due to the processing of several materials so as to produce road asphalt based on differences in the capacity of different asphalt processed. Based on the measurement results, it is found that the highest vibration occurs at the asphalt mixing plant machine seat for a capacity of 60 tons/hour where the magnitude of the deviation is $0.222 \mathrm{~mm}$ in the horizontal direction at 100 seconds, the largest velocity is $11.99 \mathrm{~mm} / \mathrm{s}$ horizontally in the second 40 $\mathrm{mm} / \mathrm{s}$ and the largest acceleration is $369.7 \mathrm{~mm} / \mathrm{s}^{2}$ in the horizontal direction of the 20th second. According to the ISO IS 2372 standard, the vibration of the Apollo ANP-1500 asphalt mixing plant machine enters class IV with a generator capacity above $75 \mathrm{KW}$, to be more precise $(150 \mathrm{KVA}=120 \mathrm{KW})$. Then it can be analyzed that the generator vibration falls into the category of "vibration within tolerance limits and is only operated for a limited time" where the highest speed is 11.99 $\mathrm{mm} / \mathrm{s}$.
\end{abstract}

Keywords: Asphalt mixing plant machine, Acceleration, Deviation

\section{PENDAHULUAN}

\subsection{Latar Belakang}

Perbandingan kapasitas pada mesin biasanya dapat menjelaskan tingkat getaran yang dihasilkan oleh mesin tersebut, sehingga dapat diketahui apakah mesin itu masih memiliki tingkat kenyamanan untuk dioperasikan. Getaran mesin atau yang bergetar adalah pergerakan bolak-balik dari sebuah mesin yang bekerja atau sebuah komponen mesin. Sehingga, setiap komponen yang bergerak bolak-balik atau berosilasi disebut bergetar. Getaran pada mesin bisa dalam beberapa bentuk., seperti getaran mesin baik yang kategori mesin kapasitas berat, mesin medium maupun mesin kapasitas ringan. Sebuah komponen mesin bisa bergetar dengan kuat, kecil, cepat atau lambat, atau tanpa suara serta menimbulkan panas. Getaran mesin tidak selamanya bisa menimbulkan kerusakan, namun ada beberapa getaran mesin yang memang dirancang untuk keperluan khusus seperti mesin penyaring (vibration screen), mesin pemadat (compactor). Oleh sebab itu peneliti ingin mengetahui bagaimana analisa karakteristik getaran pada mesin Asphalt Mixing Plant (AMP) berdasarkan kapasitas pembuatan aspal jalan pada daerah horizontal, vertikal dan longitudinal berdasarkan time domain. 
Dari latar belakang keadaan diataslah maka dipandang perlu kiranya perlu dilakukan suatu penelitian analisa karakteristik getaran pada mesin asphalt mixing plant berdasarkan kapasitas pembuatan aspal jalan 60,70 dan 80 ton/jam pada daerah horizontal, vertikal dan longitudinal berdasarkan time domain.

Dalam penelitian ini peneliti menggunakan suatu Standart ISO IS 2372 untuk standart getaran berdasarkan besarnya kecepatan yang timbul pada mesin Asphalt Mixing Plant tipe Apollo ANP-1500 sebagai acuan dengan mengukur vibrasi pada dudukan mesin dan block kabin mesin pada daerah horizontal, vertikal dan longitudinal

\subsection{Tujuan Penelitian.}

Tujuan umum dari penelitian ini adalah untuk mendapatkan bagaimana analisa karakteristik getaran pada mesin Asphalt Mixing Plant (AMP) tipe APOLLO ANP1500 berdasarkan kapasitas pembuatan aspal jalan 60, 70 dan 80 ton/jam pada daerah horizontal, vertikal dan longitudinal berdasarkan time domain, dan besarnya vibrasi pada dudukan mesin dan block kabin mesin pada daerah horizontal .vertikal dan longitudinal berupa data simpangan, kecepatan, percepatan

\subsection{Getaran Bebas (Free Vibration)}

Getaran bebas terjadi jika sistem berosilasi karena bekerjanya gaya yang ada dalam sistem itu sendiri (inherent) dan apabila tidak ada gaya luar yang bekerja.

Secara umum gerak harmonik dapat dinyatakan dengan persamaan :

$$
\mathrm{X}=\mathrm{A} \sin 2 \pi \quad 1 / \tau
$$

dimana : A adalah amplitudo osilasi yang diukur dari posisi setimbang massa.

$\tau$ adalah priode dimana gerak diulang pada $t=\tau$.

Gerak harmonik sering di nyatakan sebagai proyeksi suatu titik yang bergerak melingkar dengan kecepatan yang tetap pada suatu garis lurus seperti terlihat pada gambar 2.1 dengan kecepatan sudut garis OP sebesar $\omega$, maka perpindahan simpangan $\mathrm{x}$ dapat dituliskan sebagai:

$$
\mathrm{x}=\mathrm{A} \sin \omega \mathrm{t}
$$

Oleh karena gerak berulang dalam $2 \pi$ radian, maka didapat

$$
\omega=2 \pi / \mathrm{T}=2 \pi . \mathrm{f}
$$

Dengan menggunakan notasi titik untuk turunannya, maka didapat :

$$
\begin{aligned}
& x=\omega A \cos \omega t=\omega A \sin (\omega t+\pi / 2) \ldots \\
& \dot{x}=-\omega A \sin \omega t=\omega^{2} A \sin (\omega t+\pi) .
\end{aligned}
$$

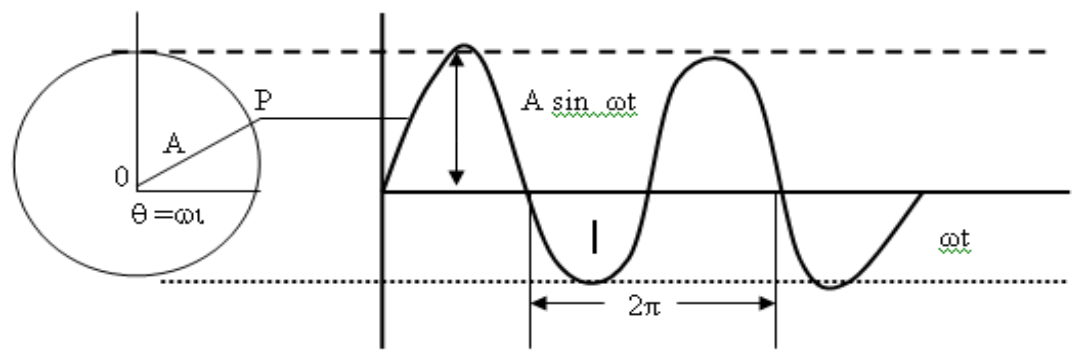

Gambar 1. Gerak harmonik sebagai proyeksi suatu titik yang bergerak pada lingkaran. 


\subsection{Getaran Paksa (Forced Vibration)}

Eksitasi harmonik sering dihadapi dalam sistem rekayasa yang biasanya dihasilkan oleh ketidak seimbangan pada mesin -mesin yang berputar. Eksitasi harmonik dapat berbentuk gaya atau simpangan beberapa titik dalam sistem. Getaran yang terjadi karena rangsangan gaya luar disebut getaran paksa.

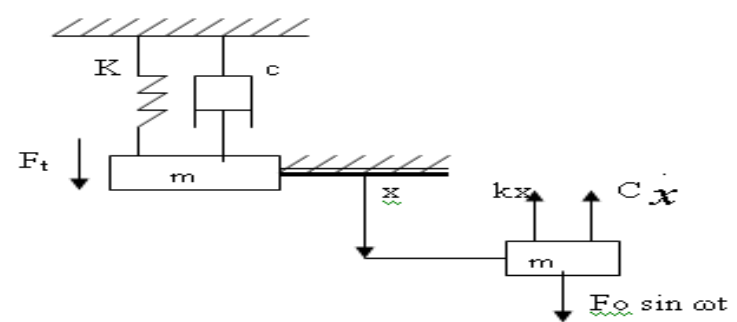

Gambar 2. Sistem yang teredam karena kekentalan dengan eksitası harmoni

Persamaan differensialnya adalah :

$. m \cdot \ddot{x}+c \dot{x}+k x=F o$ Sin $\omega t$

Solusi khusus persamaan keadaan lunak (steady state) dengan frekwensi $\omega$ yang sama dengan frekwensi eksitasi dapat diasumsikan berbentuk :

$\mathrm{x}=\mathrm{X} \sin (\omega \mathrm{t}-\Phi)$

\subsection{Landasan Teori Pengujian Getaran Mesin}

Getaran yang timbul padapada mesin asphalt mixing plant tipe Apollo ANP-1500 berdasarkan pembuatan aspal jalan berdasarkan kapasitas aspal jalan 60, 70 dan 80 ton/jam .

Dalam kondisi ini dapat diasumsikan bahwa akan terjadi torsi yang dihasilkan motor melalui mekanisme koupling. Untuk memudahkan analisa gerak, maka gambar 3 dapat disederhanakan menjadi:

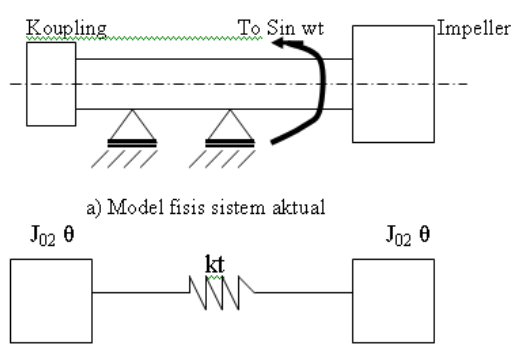

Gambar 3. Model pendekatan getaran

\subsubsection{Pengolahan data vibrasi}

Pengolahan data time domain melibatkan data hasil pengukuran objek pemantauan sinyal getaran, tekanan fluida kerja, temperatur fluida kerja maupun aliran fluida kerja. Hasil pengukuran objek pemantauan dalam domain waktu dapat berupa sinyal :

a. Sinyal statik, yaitu sinyal yang karakteristiknya (misalkan amplitudo, arah kerja) yang tidak berubah terhadap waktu.

b. Sinyal dinamik, yaitu sinyal yang karakteristiknya berubah terhadap waktu sehingga tidak konstan.

Sinyal dinamik yang sering ditemui dalam perakteknya berasal dari sinyal getaran, baik yang diukur menggunakan accelerometer, vibrometer, maupun sensor simpangan getaran . 
A

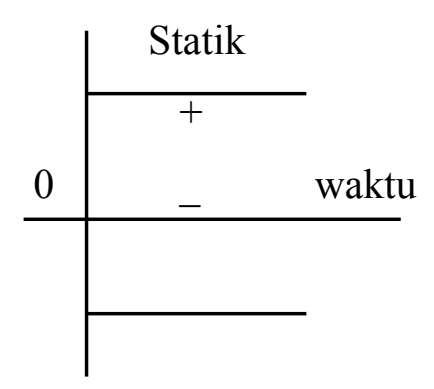

A

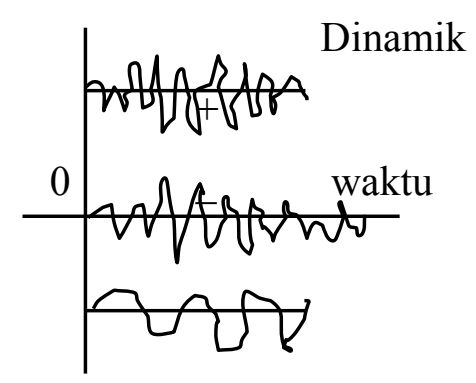

Gambar 4. Karakteristik sinyal statik dan dinamik

Untuk keperluan pengolahan sinyal getaran dalam Time Domain, perlu diperhatikan karakteristik sinyal getaran yang dideteksi oleh masing - masing sensor percepatan (Acceleration), kecepatan (Velocity) dan simpangan getaran (Displacement).

\subsection{Mesin Pembuatan Aspal Jalan (Asphalt Mixing Plant)}

Aspal ialah bahan hidro karbon yang bersifat melekat (adhesive), berbentuk padat atau setengah padat berwarna hitam kecoklatan, tahan terhadap air, dan visoelastis. Aspal sering juga disebut bitumen merupakan bahan pengikat pada campuran beraspal yang dimanfaatkan sebagai lapis perkerasan lentur .

Aspal adalah material utama pada konstruksi lapis perkerasan lentur (fleksibel pavement), jalan raya yang berfungsi sebagai campuran bahan pengikat agregat karena mempunyai daya lekat yang kuat, mempunyai sifat adhesive, kedap air dan mudah dikerjakan.

Aspal yang digunakan untuk mateial jalan terdiri dari beberapa jenis yaitu :

- Aspal alam

- Aspal buatan ( bitumen)

- Ter

Bahan dasar aspal diperoleh dari tambang/alam, dapat terjadi dari aspal danau, batu kapur aspal dan batu pasir aspal serta mastik aspal. Hasil sampingan dari proses pemurnian minyak dalam proses pembuatan aspal minyak bumi, mula-mula dari suatu sumur minyak yang bercampur pasir dan air. Minyak bumi disedot keluar, ditempatkan dalam tangki lapangan. Kemudian dialirkan ke gardu pompa untuk selanjutnya dipompa ke dalam tangki pengilangan. Setelah bejana pipa dan bejana lain dengan pemanasan pada suhu tertentu dalam proses yang kemudian dihasilkan destilat ringan ,destilat sedang, destilat berat dan destilat residu, dari destilat - destilat ini dalam suatu prosesing dihasilkan :

-Bensin, pelarut ringan

-Minyak tanah, minyak bakar ringan

- Minyak Diesel

- Minyak Pelumas

Dari bahan residu dihasilkan minyak bakar residu. Bahan residu setelah diproses lagi dihasilkan aspal padat, semen aspal dengan penetrasi tertentu ,serta bahan aspal cair, dialirkan ke instalasi emulsi dihasilkan aspal emulsi. 


\section{METODE PENELITIAN}

\subsection{Bahan}

Dalam penelitian ini subjek penelitian adalah mesin asphalt mixing plant seperti terlihat pada gambar dibawah ini.
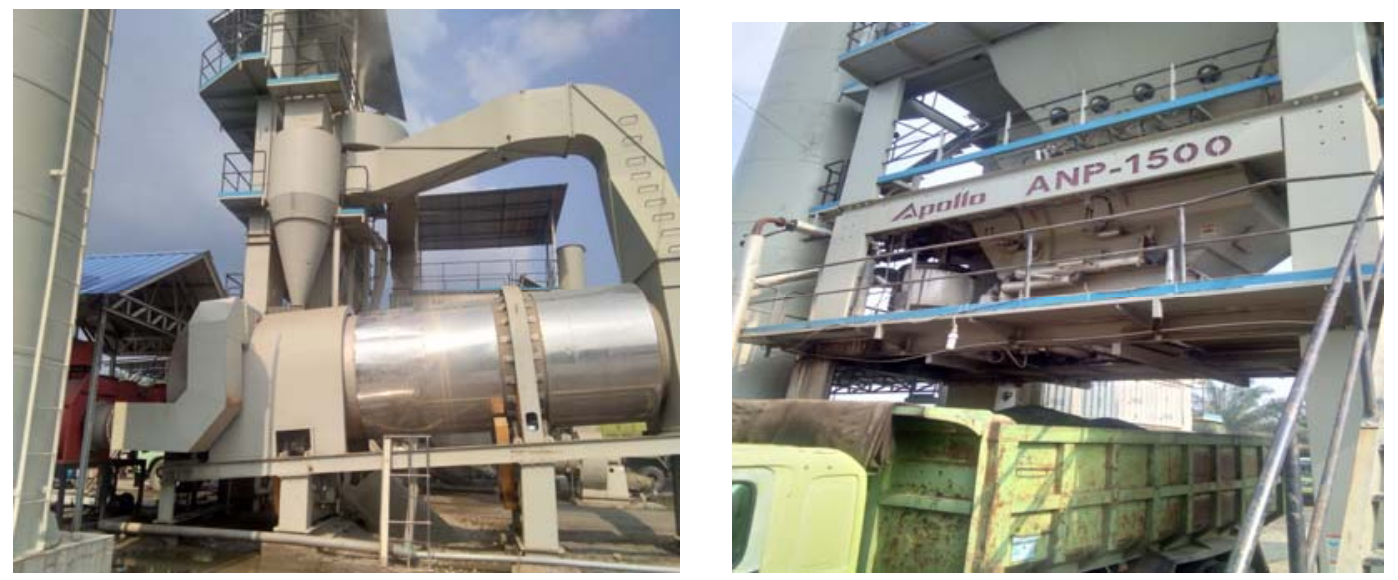

Gambar 5. Mesin Asphalt Mixing Plant

\subsection{Peralatan Dan Metode}

\section{Vibrometer}

Untuk melakukan pengukuran terhadap tingkat vibrasi yang terjadi pada dudukan mesin dan block kabin digunakan instrumen pengukur sinyal vibrasi, yaitu vibrometer digital Handheld 908B. Setting instrumen pengukur vibrasi ini dilakukan pada saat akan melakukan pengukuran sinyal vibrasi.

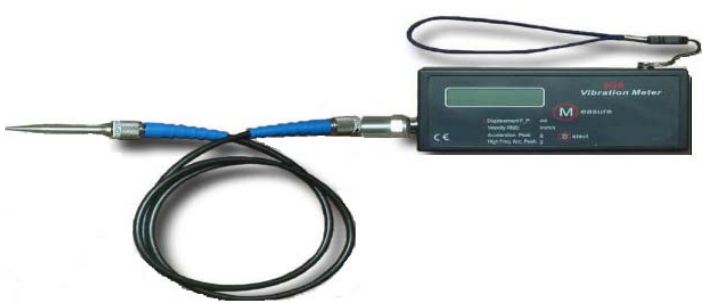

Gambar 6. Vibrometer Handheld

\subsection{Variabel Yang Diamati}

- Displacement atau simpangan dari satu titik dan tiga arah pengukuran.

- Velocity atau kecepatan dari satu titik dan tiga arah pengukuran.

- Acceleration atau percepatan dari satu titik dan tiga arah pengukuran.

\section{HASIL DAN PEMBAHASAN}

Penelitian ini memperoleh data pengukuran getaran pada mesin dan dudukan Asphalt Mixing Plant (AMP) tipe Apollo ANP-1500 sebagai berikut: 
Tabel 1. Hasil pengukuran respon getaran pada mesin asphalt mixing plant untuk Kapasitas 60 ton/jam

\begin{tabular}{|c|c|c|c|c|c|c|c|c|c|c|}
\hline \multirow{2}{*}{$\begin{array}{l}\mathrm{N} \\
\mathrm{o}\end{array}$} & $\begin{array}{l}\text { W } \\
\mathrm{a}\end{array}$ & \multicolumn{3}{|c|}{ Vertikal } & \multicolumn{3}{|c|}{ Horizontal } & \multicolumn{3}{|c|}{ Longitudinal } \\
\hline & $\begin{array}{l}\mathrm{u} \\
(\mathrm{s})\end{array}$ & $\begin{array}{l}\text { Disp } \\
m m\end{array}$ & $\begin{array}{c}\text { Vel } \\
\mathrm{mm} / \mathrm{s}\end{array}$ & $\begin{array}{c}\text { Acc } \\
\mathrm{mm} / \mathrm{s}^{2}\end{array}$ & $\begin{array}{l}\text { Disp } \\
\mathrm{mm}\end{array}$ & $\begin{array}{c}\mathrm{Vel} \\
m m / s\end{array}$ & $\begin{array}{c}\text { Acc } \\
\mathrm{mm} / \mathrm{s}^{2}\end{array}$ & $\begin{array}{l}\text { Disp } \\
m m\end{array}$ & $\begin{array}{c}\text { Vel } \\
\mathrm{mm} / \mathrm{s}\end{array}$ & $\begin{array}{c}\text { Acc } \\
\mathrm{mm} / \mathrm{s}^{2}\end{array}$ \\
\hline 1. & 10 & 0,187 & 7,00 & 277,4 & 0,175 & 6,92 & 270,6 & 0,182 & 6,82 & 273,3 \\
\hline 2. & 20 & 0,183 & 6,97 & 287,1 & 0,179 & 6,95 & 262,6 & 0,182 & 6,80 & 269,6 \\
\hline 3. & 30 & 0,185 & 7,04 & 272,7 & 0,170 & 7,03 & 269,9 & 0,175 & 6,88 & 278,8 \\
\hline 4. & 40 & 0,187 & 7,09 & 279,5 & 0,173 & 7,05 & 265,3 & 0,179 & 6,78 & 282,9 \\
\hline 5. & 50 & 0,185 & 6,92 & 285,5 & 0,176 & 6,97 & 261,8 & 0,175 & 6,75 & 277,9 \\
\hline 6. & 60 & 0,179 & 6,98 & 280,4 & 0,183 & 6,91 & 277,4 & 0,173 & 6,82 & 271,6 \\
\hline 7. & 70 & 0,177 & 6,89 & 271,7 & 0,179 & 6,86 & 271,2 & 0,176 & 6,89 & 267,7 \\
\hline 8. & 80 & 0,180 & 6,94 & 281,3 & 0,183 & 6,84 & 263,6 & 0,180 & 6,84 & 275,2 \\
\hline 9. & 90 & 0,178 & 6,86 & 276,8 & 0,180 & 6,89 & 279,8 & 0,178 & 6,79 & 271,9 \\
\hline 10 & 100 & 0,181 & 6,80 & 279,3 & 0,178 & 6,95 & 270,3 & 0,175 & 6,86 & 266,7 \\
\hline \multicolumn{2}{|r|}{ rata } & 0,182 & 6,94 & 279,1 & $\mathbf{0 , 1 7 7}$ & 6,93 & 269,2 & $\mathbf{0 , 1 7 7}$ & 6,82 & 273,5 \\
\hline
\end{tabular}

Dari tabel 1 dapat diplot data simpangan, kecepatan dan percepatan dengan waktu untuk Hasil pengukuran respon getaran pada mesin asphalt mixing plant untuk kapasitas 60 ton/jam seperti gambar 7 .

Simpangan, Kecepatan, Percepatan

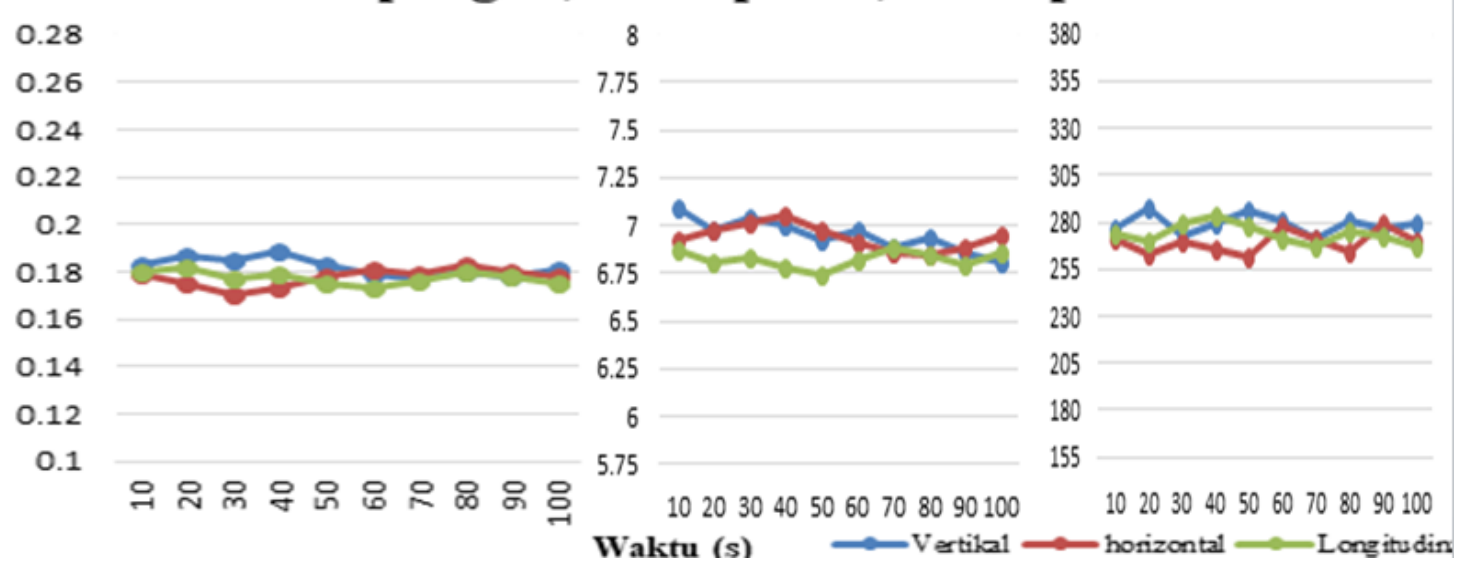

Gambar 7. Grafik gabungan dari simpangan, kecepatan dan percepatan pada mesin asphalt mixing plant 
Kecepatan sudut untuk masing-masing arah dapat dihitung dari tabel 1 yaitu :

\section{Arah vertikal}

Kecepatan sudutnya :

$$
\begin{aligned}
& \vec{\omega}=\sqrt{\frac{1}{\alpha}}=\sqrt{\frac{229_{, 1}}{0,182}}=\sqrt{1533,52}=39,16 \mathrm{rad} / \mathrm{s} \\
& \vec{\omega} t=\operatorname{arc} \cdot \tan \frac{\pi \bar{\alpha}}{\hbar}=\operatorname{arc} \cdot \tan \frac{0,182}{6,94} \times 39,16=\operatorname{arc} \cdot \tan 1,03=45,76 \mathrm{rad}
\end{aligned}
$$

Sehingga diperoleh periode $: \mathrm{t}=\frac{\varpi t}{\varpi}=\frac{48,74}{39,39}=1,17 \mathrm{~s}$

Amplitudo adalah : $\quad \mathrm{A}=\frac{x}{\operatorname{Sin} \varpi t}=\frac{0,182}{\sin 48,76 \times 1,17}=\frac{0,182}{0,72 \times 1,17}=0,22 \mathrm{~mm}$

Dengan cara perhitungan yang sama, maka akan didapatkan hasil untuk kecepatan sudut, perioda, dan amplitudo untuk arah horizontal dan longitudinal seperti pada tabel dibawah ini:

Tabel 2. Hasil perhitungan getaran pada mesin asphalt mixing plant untuk Kapasitas 60 ton/jam

\begin{tabular}{|l|l|l|l|}
\hline \multirow{2}{*}{ Variabel } & \multicolumn{3}{|c|}{ Arah } \\
\cline { 2 - 4 } & \multicolumn{1}{|c|}{ Vertikal } & \multicolumn{1}{|c|}{ Horizontal } & Longitudinal \\
\hline $\bar{\omega}(\mathrm{rad} / \mathrm{s})$ & 39,16 & 38,99 & 39,31 \\
\hline $\bar{\omega} \mathrm{t}(\mathrm{rad})$ & 45,76 & 44,89 & 45,57 \\
\hline $\mathrm{t}(\mathrm{s})$ & 1,17 & 1,15 & 1,16 \\
\hline $\mathrm{A}(\mathrm{mm})$ & 0,25 & 0,25 & 0,25 \\
\hline
\end{tabular}

\section{KESIMPULAN}

1. Berdasarkan hasil pengukuran diperoleh bahwa besar getaran yang terjadi paling tinggi pada dudukan mesin asphalt mixing plant untuk kapasitas 60 ton/jam dimana besarnya simpangan $0,222 \mathrm{~mm}$ arah horizontal pada detik ke 100, kecepatan (velocity) terbesar $11,99 \mathrm{~mm} / \mathrm{s}$ arah horizontal pada detik 40 dan besarnya percepatan (accleration) terbesar $369,7 \mathrm{~mm} / \mathrm{s}^{2}$ arah horizontal detik ke 20.

2. Sesuai standard ISO IS 2372 maka getaran Mesin Asphalt Mixing Plant Apollo ANP-1500 tersebut masuk ke golongan kelas IV dengan kapasitas generator diatas $75 \mathrm{KW}$, lebih tepatnya $(150 \mathrm{KVA}=120 \mathrm{KW})$. Maka dapat dianalisa bahwa getaran generator masuk ke kategori "getaran dalam batas toleransi dan hanya dioperasikan dalam waktu terbatas" dimana kecepatan tertinggi yaitu 11,99 mm/s arah Horizontal saat detik ke 40.

6. DAFTAR PUSTAKA

Acoustical System And Tecnologies, Saint Petersburg, Russia ,2004.

Bagiasna, K., " Analisis Sinyal Getaran, " PT. Krakatau Engineering.

Barkov, A. V, Barkova, N.A, “ Artificial Inteligence System For

MachineCondition and Diagnosties by vibration," Proccedings of the

SaintPeterburg, USA, 1991

Bodre, R,"The Principles of Vibration theory and Analysis," DLI Engineering Corp Bainbridge Island, W A 98110. 
B.H Amstead ,Teknologi Mekanik jilid 1 dan 2 , Penerbit Erlangga ,1986.

Dynamometer, < http://www. Asynchronous dynamometer.com $>$

Dynaseq, Monitoring group, 12 Juli 2006, , http: // www. Dynaseq.co.uk.>.

VibrationTesting Equipment For “

Proses pembuatan aspal jalan (Asphalt Mixing Plant)

https://hermantechnicind.blogspot.com.

Jenis Material Aspal Untuk Kebutuhan ( Konstruksi Jalan /Kegunaan Aspal)

https://readymixbdg.com. 